\title{
Effect of dietary seaweed extracts and fish oil supplementation in sows on performance, intestinal microflora, intestinal morphology, volatile fatty acid concentrations and immune status of weaned pigs
}

\author{
S. G. Leonard ${ }^{1,2}$, T. Sweeney ${ }^{1}$, B. Bahar ${ }^{1}$, B. P. Lynch $^{2}$ and J. V. O’Doherty ${ }^{1 *}$ \\ ${ }^{1}$ UCD School of Agriculture, Food Science and Veterinary Medicine, Lyons Research Farm, University College Dublin, \\ Newcastle, County, Dublin, Republic of Ireland \\ ${ }^{2}$ Pig Production Department, Teagasc, Moorepark Research Centre, County Cork, Republic of Ireland \\ (Received 17 March 2010 - Revised 19 July 2010 - Accepted 25 August 2010 - First published online 28 September 2010)
}

\section{Abstract}

A $2 \times 2$ factorial experiment (ten sows per treatment) was conducted to investigate the effect of maternal dietary supplementation with a seaweed extract (SWE; $0 v \cdot 10.0 \mathrm{~g} / \mathrm{d}$ ) and fish oil (FO; $0 v \cdot 100 \mathrm{~g} / \mathrm{d}$ ) inclusion from day 109 of gestation until weaning (day 26) on pig performance post-weaning (PW) and intestinal morphology, selected microflora and immune status of pigs $9 \mathrm{~d}$ PW. The SWE contained laminarin (10\%), fucoidan (8\%) and ash (82\%) and the FO contained $40 \%$ EPA and $25 \%$ DHA. Pigs weaned from SWE-supplemented sows had higher daily gain $(P=0.063)$ between days 0 and $21 \mathrm{PW}$ and pigs weaned from FO-supplemented sows had higher daily gain $(P<0 \cdot 05)$ and gain to feed ratio $(P<0 \cdot 01)$ between days 7 and $14 \mathrm{PW}$. There was an interaction between maternal SWE and FO supplementation on caecal Escherichia coli numbers $(P<0.05)$ and the villous height to crypt depth ratio in the ileum $(P<0 \cdot 01)$ and jejunum $(P<0 \cdot 05)$ in pigs 9d PW. Pigs weaned from SWE-supplemented sows had lower caecal E. coli and a higher villous height to crypt depth ratio in the ileum and jejunum compared with non-SWE-supplemented sows $(P<0 \cdot 05)$. There was no effect of SWE on $E$. coli numbers and villous height to crypt depth ratio with FO inclusion. Maternal FO supplementation induced an increase in colonic mRNA abundance of IL-1 $\alpha$ and IL-6 $(P<0 \cdot 05)$, while SWE supplementation induced an increase in ileal TNF- $\alpha(P<0 \cdot 01)$ and colonic TFF3 mRNA expression $(P<0 \cdot 05)$. In conclusion, these results demonstrate that SWE and FO supplementation to the maternal diet influenced the gastrointestinal environment and performance of the weaned pig.

Key words: Fish oil: Fucoidan: Laminarin: Gastrointestinal health: Seaweed extract: Weaned piglets

Under conventional practice, the weaning transition is often associated with undesirable morphological and physiological changes in the piglet's gastrointestinal environment caused by a reduced voluntary feed intake, thus increasing susceptibility to intestinal dysfunction ${ }^{(1)}$. Numerous investigations have demonstrated that abrupt weaning is associated with intestinal inflammation, villous atrophy, crypt hyperplasia and reduced epithelial brush border activity ${ }^{(1-4)}$. The traditional measures to reduce or ameliorate weaningassociated intestinal dysfunction are centred on dietary inclusion of antibiotic growth promoters to the weanling diet; however, present European legislation prohibits antibiotic growth promoters incorporation to animal diets.

Evidence suggests that dietary provision of long-chain $n$ - 3 PUFA to experimental animals modulates both the intensity and duration of inflammatory immune responses ${ }^{(5)}$. Previous studies also indicated that marine oil inclusion to the maternal diet reduced pre-weaning piglet mortality ${ }^{(6)}$, enhanced suckling piglet performance ${ }^{(7)}$ and increased serum IgG concentrations at weaning ${ }^{(8)}$. However, studies examining the influence of maternal fish oil (FO) supplementation on piglet health status beyond the suckling period are limited. Rooke et $a l .{ }^{(9)}$ reported that pigs weaned from sows supplemented with tuna oil during lactation were heavier $7 \mathrm{~d}$ post-weaning (PW) compared with those offered linseed oil. In contrast, maternal FO supplementation was shown to exert no influence on pig performance PW; however, these authors observed that the fatty acid composition of plasma and adipose tissue of pigs PW was largely influenced by dietary treatment of sows ${ }^{(10)}$.

Recent investigations have focussed on the exploitation of marine algae and the identification of novel bioactive compounds containing immunomodulatory properties ${ }^{(11-13)}$. Evidence indicates that dietary provision of a Laminaria

Abbreviations: ADG, average daily gain; FO, fish oil; PW, post-weaning; SWE, seaweed extract. 
spp.-derived seaweed extract (SWE) containing laminarin and fucoidan is beneficial to weanling pigs, by enhancing growth performance ${ }^{(13,14)}$ and intestinal microflora through a reduced enteric Enterobacteriaceae population ${ }^{(12)}$. Furthermore, other studies have shown that SWE supplementation may alter the inflammatory response through regulating the expression of cytokines and chemokines ${ }^{(12)}$ and altering mucin gene expression ${ }^{(15,16)}$. Leonard et $a .^{(17)}$ recently demonstrated that piglets suckling SWE-supplemented sows had greater circulatory IgG concentrations on days 5 and 12 of lactation and a greater percentage of Escherichia coli-phagocytising leucocytes at weaning; however, these authors observed no effect of dietary treatment on average piglet weaning weight. To our knowledge, no study has examined the effect of maternal supplementation with SWE on growth performance and aspects of gastrointestinal health of weaned pigs.

Laminarin is composed of $\beta$ - $(1 \rightarrow 3)$-linked glucans with $\beta$-( $1 \rightarrow 6)$-linked side chains of varying distribution and length ${ }^{(18,19)}$. $\beta$-Glucans have the capacity to modulate immune function through stimulating the release of cytokines and chemokines, thus activating leucocytes including monocytes, macrophages and lymphocytes ${ }^{(20)}$. Fucoidans represent a group of sulphated polysaccharides, extracted from the extracellular matrix of various species of brown seaweeds ${ }^{(21)}$

The primary objective of the present study was to examine the influence of maternal dietary supplementation with a SWE and FO from day 109 of gestation until weaning (day 26) on growth performance of weaned pigs. Furthermore, the present study investigated the effect of maternal dietary treatment on intestinal morphology, selected intestinal microflora, volatile fatty acid concentrations and mRNA expression of genes that regulate inflammatory responses (IL-1 $\alpha$, IL-6, 1L-10 and $\mathrm{TNF}-\alpha$ ), mucosal repair (TFF3) and mucin secretion (MUC2) in the ileum and colon of pigs $9 \mathrm{~d}$ PW.

\section{Materials and methods}

All experimental procedures used in the present study were conducted under experimental license from the Irish Department of Health in accordance with the Cruelty to Animals Act 1876 and the European Communities (Amendments of the Cruelty to Animals Act, 1876) Regulations, 1994.

\section{Experimental design and treatment}

The experiment was designed as a $2 \times 2$ factorial arrangement comprising four dietary treatments. Forty crossbred pregnant sows (Large White $\times$ Landrace genetic lines) were randomly assigned, accounting for parity and expected delivery date to one of four dietary treatments (ten sows per treatment): (1) basal lactation diet; (2) basal lactation diet and 10.0 g/d of SWE; (3) basal lactation diet and $100 \mathrm{~g} / \mathrm{d}$ of FO; (4) basal lactation diet and $10 \cdot 0 \mathrm{~g} / \mathrm{d}$ of SWE and $100 \mathrm{~g} / \mathrm{d}$ of FO from day 109 of gestation until weaning (day 26). The level of SWE used in the present study is based on previous work by Leonard et al. ${ }^{(17)}$ and Lynch et al. ${ }^{(22)}$. The level of FO used in the present study is based on work by Boudry et al. ${ }^{(23)}$.

The SWE supplement (10g) contained laminarin $(100 \mathrm{~g} / \mathrm{kg})$, fucoidan $(80 \mathrm{~g} / \mathrm{kg})$ and ash $(820 \mathrm{~g} / \mathrm{kg})$ and was extracted from a Laminaria spp. The SWE was sourced from Bioatlantis Limited (Kerry Technology Park, Tralee Company, Kerry, Ireland). The ash content of the SWE was $15 \mathrm{~g} / \mathrm{kg} \mathrm{Ca}, 10 \mathrm{~g} / \mathrm{kg} \mathrm{Na}, 10 \mathrm{~g} / \mathrm{kg} \mathrm{K}, 10 \mathrm{~g} / \mathrm{kg}$ $\mathrm{S}, 250 \mathrm{mg} / \mathrm{kg}$ iodine, $250 \mathrm{mg} / \mathrm{kg} \mathrm{Fe}, 20 \mathrm{mg} / \mathrm{kg} \mathrm{Cu}$ and $50 \mathrm{mg} / \mathrm{kg} \mathrm{Zn}$. The FO was sourced from Trouw Nutrition (Belfast, UK) and the analysed fatty acid composition is presented in Table 1. The FO was derived from anchovy, sardine and salmon oil; however, the oil was distilled in order to concentrate the EPA and DHA content.

The ingredient composition of the lactation diet is presented in Table 2. Diets were formulated to contain similar concentrations of crude protein $(192 \mathrm{~g} / \mathrm{kg})$, digestible energy $(14 \mathrm{MJ} / \mathrm{kg})$ and total lysine $(10 \cdot 1 \mathrm{~g} / \mathrm{kg})$. The amino acid requirements were met relative to lysine ${ }^{(24)}$. Sows received specific amounts of feed in the following quantities: $2 \mathrm{~kg} / \mathrm{d}$ of diet until the day of farrowing (day 0 ) and then the feed supply was increased by $1 \mathrm{~kg} / \mathrm{d}$ until day 4 and then by $0.5 \mathrm{~kg} / \mathrm{d}$ until day 6 . Afterwards, they were allowed ad libitum consumption of the standard lactation diet which was adjusted for each sow depending on daily intake. The sows were fed in two equal meals provided at 09.00 and 15.00 hours. The standard lactation

Table 1. Fatty acid composition of fish oil ${ }^{*}$

(Mean values and standard deviations)

\begin{tabular}{|c|c|c|}
\hline \multirow[b]{2}{*}{ Fatty acid } & \multicolumn{2}{|c|}{ Fatty acid (\%) } \\
\hline & Mean & SD \\
\hline C14:0 & 0.14 & 0.01 \\
\hline C15: 1 & 0.14 & 0.09 \\
\hline C16:0 & $2 \cdot 27$ & 0.35 \\
\hline C16: 1 & 1.04 & 0.06 \\
\hline C17:0 & 0.19 & 0.07 \\
\hline C17:1 & 0.07 & 0.01 \\
\hline C18:0 & 3.64 & 0.21 \\
\hline C18: 1 (n-9 cis) & $5 \cdot 70$ & 0.45 \\
\hline C18: 1 ( $n-9$ trans) & 0.08 & 0.01 \\
\hline C18:2 $(n-6)$ & 1.54 & 0.02 \\
\hline C18: $3(n-3)$ & 0.89 & 0.04 \\
\hline C18: $3(n-6)$ & 0.19 & 0.02 \\
\hline C20: 1 & $3 \cdot 36$ & 0.10 \\
\hline C20:2 & 3.00 & 0.22 \\
\hline C20 : $3(n-3)$ & 0.32 & 0.03 \\
\hline $\mathrm{C} 20: 3(n-6)$ & 0.43 & 0.04 \\
\hline $\mathrm{C} 20: 4(n-6)$ & 1.98 & 0.09 \\
\hline C20: 5 (n-3) & 39.05 & 0.54 \\
\hline C22:0 & 0.50 & 0.04 \\
\hline C22: $1(n-9)$ & 1.31 & 0.32 \\
\hline $\mathrm{C} 22: 2$ & $2 \cdot 37$ & 0.04 \\
\hline C22: $6(n-3)$ & $24 \cdot 25$ & 0.14 \\
\hline $\mathrm{C} 24: 0$ & 0.47 & 0.09 \\
\hline C24: 1 & 0.28 & 0.02 \\
\hline
\end{tabular}

* Supplied by Trouw Nutrition (Belfast, UK). 
Table 2. Composition and chemical analysis of basal lactation and weaning diet*

\begin{tabular}{|c|c|c|}
\hline & $\begin{array}{l}\text { Lactation diet } \\
(\mathrm{g} / \mathrm{kg})\end{array}$ & $\begin{array}{l}\text { Weaning diet } \\
(\mathrm{g} / \mathrm{kg}) \dagger \ddagger\end{array}$ \\
\hline \multicolumn{3}{|l|}{ Ingredients } \\
\hline Whey permeate & & 125 \\
\hline Wheat & 288 & $444 \cdot 2$ \\
\hline Barley & 300 & \\
\hline Soyabean meal & 242 & $142 \cdot 5$ \\
\hline Beat pulp & 100 & \\
\hline Whey protein isolate & & 130 \\
\hline Full-fat soyabean & & 80 \\
\hline Soya oil & 45 & 65 \\
\hline Vitamins and minerals & 2.5 & 5 \\
\hline Limestone & $15 \cdot 0$ & \\
\hline Dicalcium phosphate & 7.5 & \\
\hline Lys $\mathrm{HCl}$ & & 4.5 \\
\hline DL-Met & & 1.6 \\
\hline L-Thr & & $2 \cdot 2$ \\
\hline \multicolumn{3}{|l|}{ Analysis } \\
\hline DM & 891.0 & $892 \cdot 5$ \\
\hline $\mathrm{CP}(\mathrm{N} \times 6.25)$ & $192 \cdot 0$ & $224 \cdot 2$ \\
\hline Gross energy (MJ/kg) & $16 \cdot 5$ & $18 \cdot 2$ \\
\hline Ash & $49 \cdot 2$ & 43.7 \\
\hline Neutral-detergent fibre & $147 \cdot 8$ & $110 \cdot 3$ \\
\hline Lys§ & $10 \cdot 1$ & $16 \cdot 5$ \\
\hline Met and Cys§ & $6 \cdot 0$ & $9 \cdot 9$ \\
\hline Thr§ & 6.5 & $10 \cdot 7$ \\
\hline Tryptophan§ & 1.8 & 2.5 \\
\hline $\mathrm{Ca} \S$ & 8.0 & $8 \cdot 0$ \\
\hline $\mathrm{P} \S$ & $6 \cdot 0$ & $6 \cdot 0$ \\
\hline
\end{tabular}

$\mathrm{CP}$, crude protein.

${ }^{*}$ As-fed basis.

†Weaner diet provided (mg/kg completed diet): $\mathrm{Cu}, 175 ; \mathrm{Fe}, 140 ; \mathrm{Mn}, 47 ; \mathrm{Zn}, 120$; iodine, 0.6; Se, 0.3; retinal, 1.8; cholecalciferol, 0.025; $\alpha$-tocopherol, 67; phytylmenaquinone, 4; cyanocobalamin, 0.01; riboflavin, 2; nicotinic acid, 12; pantothenic acid, 10; choline chloride, 250; thiamine, 2; pyridoxine, 0.015.

¥ Sow diet provided (mg/kg completed diet): $\mathrm{Cu}, 25 ; \mathrm{Fe}, 140 ; \mathrm{Mn}, 47 ; \mathrm{Zn}, 120$; iodine, 0.6; Se, 0.3; retinal, 1.8; cholecalciferol, 0.025; $\alpha$-tocopherol, 67; phytylmenaquinone, 4; cyanocobalamin, 0.01 ; riboflavin, 2; nicotinic acid, 12; pantothenic acid, 10; choline chloride, 250; thiamine, 2; pyridoxine, 0.015. $\S$ Calculated from tabulated nutritional composition ${ }^{(56)}$.

diet was top-dressed each morning (9.00 hours) with experimental supplements to ensure consumption. The non-FO treatment groups (experimental diets 1 and 2) received $100 \mathrm{~g} / \mathrm{d}$ of soyabean oil.

\section{Sow management}

The experiment was initiated on day 109 of gestation when the sows were moved to farrowing pens. The sows were individually housed in farrowing pens $(2 \cdot 2 \times 2.4 \mathrm{~m})$ with slated floors and heat pads for the piglets. The farrowing room temperature was maintained at $20^{\circ} \mathrm{C}$. The sows were individually fed and had ad libitum access to water via individual nipple drinkers throughout the entire study. No creep feed was offered to piglets throughout the experimental period.

\section{Piglet management}

Farrowings were not induced and were supervised. The number of live born piglets, individual piglet birth weight and weaning weight were recorded. All piglets were tagged at birth. Litter size was adjusted shortly after birth by cross-fostering (eleven piglets per sow) within treatments to ensure that sows nursed a similar number of piglets and was maintained throughout the suckling period.

At weaning, a total of 120 mixed-sex pigs (three pigs/ litter; two males and one female) with an average live weight of 8.05 (SD 0.46) kg were selected and offered a starter diet for $21 \mathrm{~d}$. These pigs were not cross-fostered piglets. The pigs were housed in groups of three (from original sow litter) on fully slatted floors $(1.68 \times 1.22 \mathrm{~m})$. Feed and water were available ad libitum throughout the experimental period. The ambient environmental temperature within the houses was thermostatically controlled. The temperature was maintained at $30^{\circ} \mathrm{C}$ for the first week and was reduced by $2^{\circ} \mathrm{C} /$ week thereafter. Pigs were individually weighed on days $0,7,14$ and 21 and feed intake was recorded on a daily basis.

The ingredient composition and chemical analysis of the starter diet are presented in Table 2. Diets were formulated to contain similar concentrations of crude protein $(210 \mathrm{~g} / \mathrm{kg})$, digestible energy $(16 \mathrm{MJ} / \mathrm{kg})$ and standardised ileal digestible lysine $(14.5 \mathrm{~g} / \mathrm{kg})$. All amino acid requirements were met relative to standardised ileal digestible lysine ${ }^{(24)}$. No medication, $\mathrm{ZnO}$ or growth-promoting agents were included in the starter diet.

In addition, the effect of maternal SWE and FO supplementation on aspects of gastrointestinal health and immune status in pigs 9d PW was examined. At weaning, one pig/litter (female piglet) with an average live weight of 8.0 (SD 0.24) kg was selected and offered a similar starter diet (Table 2) for $9 \mathrm{~d}$. The pigs were housed individually. At day 9 PW, the pigs were killed following a lethal injection of Euthatal (pentobarbitone sodium Patent Blue) at a rate of $1 \mathrm{ml} / 1.4 \mathrm{~kg}$ live body weight.

\section{Analysis of small-intestinal histology}

The digestive tract was immediately removed aseptically and sections of the duodenum ( $10 \mathrm{~cm}$ from the stomach), jejunum $(60 \mathrm{~cm}$ from the stomach) and the ileum $(15 \mathrm{~cm}$ from the caecum) were excised and fixed in $10 \%$ phosphate-buffered formalin. The preserved segments were prepared using standard paraffin-embedding techniques. Cross-sections at $5 \mu \mathrm{m}$ thickness of each intestinal segment were stained with haemotoxylin and eosin. Villous height and crypt depth were measured on the stained sections $(10 \times$ objective) using a light microscope fitted with an image analyser (Image Pro Plus; Media Cybernetics, Bethesda, MD, USA). Lengths of twenty well-orientated intact villi and their associated crypt were measured in duplicate for each segment. The villous height was measured from the crypt-villous junction to the tip of the villous and the crypt depth was measured from the crypt-villous junction to the base. The results were expressed as the mean villous height or crypt depth in $\mu \mathrm{m}$. 


\section{Analysis of selected microbial populations}

Digesta samples (approximately 10 (SD 1) g) were ascetically recovered from the caecum and colon of each pig immediately post-slaughter, stored in sterile containers (Sarstedt, Wexford, Republic of Ireland) on ice and immediately transported to the laboratory. Populations of Bifidobacterium spp., E. coli and Lactobacillus spp. were selectively isolated and enumerated according to the method described by Pierce et al. ${ }^{(25)}$. A $1.0 \mathrm{~g}$ sample was removed from each digesta samples, serially diluted (1:10) in $9.0 \mathrm{ml}$ aliquots of maximum recovery diluent (Oxoid, Basingstoke, UK) and spread plated $(0.1 \mathrm{ml}$ aliquots) onto selective agars, as follows: Bifidobacterium spp. were isolated on Wilkins Chalgren agar (Oxoid), containing 5\% (v/v) defibrinated blood (Biological Laboratories Europe, Mayo, Republic of Ireland) with anaerobic incubation for $24-48 \mathrm{~h}$ in a Wise Anaerobic Chamber (Don Whitley Scientific, Shipley, West Yorkshire, UK) at $37^{\circ} \mathrm{C}$ with an atmosphere of $10 \% \mathrm{H}_{2}, 10 \% \mathrm{CO}_{2}$ and $80 \% \mathrm{~N}_{2}$. Suspect Bifidobacterium spp. were confirmed with Analytical Profile Index (API) 50 CHL (BioMerieux, Marcy l'Etoile, France). Lactobacillus spp. were isolated on de Man, Rogosa and Sharp agar (Oxoid) with overnight $(18-24 \mathrm{~h})$ incubation at $37^{\circ} \mathrm{C}$ in a $5 \% \mathrm{CO}_{2}$ environment, as recommended by the manufacturers (Oxoid). The API 50 CHL (BioMerieux) kit was used to confirm suspect Lactobacillus spp. The E. coli species were isolated on McConkey agar (Oxoid), following aerobic incubation at $37^{\circ} \mathrm{C}$ for $18-24 \mathrm{~h}$. Suspect colonies were confirmed with API 20E (BioMerieux). This API system identifies the suspect colonies by measuring their ability to produce cytochrome oxidase. Typical colonies of each bacterium were counted, log transformed and presented per gram of digesta.

\section{Volatile fatty acid analysis and $\mathrm{pH}$ measurement}

Samples of digesta from the caecum and colon of individual pigs were recovered for volatile fatty acid analysis. The volatile fatty acid concentrations in the digesta were determined by a gas chromatographic method following the procedures of Pierce et al. ${ }^{(26)}$. The $\mathrm{pH}$ of digesta samples from the caecum and colon were determined immediately post-slaughter. Samples were placed in universal containers and $\mathrm{pH}$ measurements were made using a Mettler Toledo MP 220 pH meter, which was calibrated using certified $\mathrm{pH} 4$ and 7 buffer solutions.

\section{Ileum and colon gene expression}

RNA extraction and complementary DNA synthesis. Tissue samples were collected from the ileum and colon, rinsed with ice-cold PBS and immediately placed into tubes containing RNAlater (Ambion, Inc., Austin, TX, USA) and stored at $-20^{\circ} \mathrm{C}$ until used for RNA extraction. Total RNA was extracted from $25 \mathrm{mg}$ each of the ileum and colon tissue samples using a Gene Elute Mammalian Total RNA Miniprep Kit (Sigma-Aldrich, St Louis, MO, USA) according to the manufacturer's instructions. To eliminate possible genomic DNA contamination, total RNA samples were subjected to DNAse I (Sigma Aldrich) treatment which was followed by RNA purification using a phenol-chloroform extraction method. The total RNA was quantified using a NanoDrop-ND1000 spectrophotometer (Thermo Fisher Scientific, Inc., Boston, MA, USA) and the purity was assessed by determining the ratio of the absorbance at 260 and $280 \mathrm{~nm}$. All the total RNA samples had $260 / 280 \mathrm{~nm}$ ratios above $1 \cdot 8$. In addition, RNA integrity was verified by visualisation of the $18 \mathrm{~S}$ and 28S ribosomal RNA bands stained with ethidium bromide after agarose gel electrophoresis (E-Gel; Invitrogen, Carlsbad, CA, USA). Total RNA ( $1 \mu \mathrm{g}$ ) was reverse transcribed with a First Strand cDNA Synthesis Kit (Fermentas, Glen Burnie, MD, USA) using oligodeoxythymidylic acid primers following the manufacturer's instructions. The final reverse-transcribed product was adjusted to a volume of $120 \mu \mathrm{l}$ using nuclease-free water.

\section{Quantitative real-time PCR}

Quantitative real-time PCR assays were performed on complementary DNA samples in ninety-six-well optical plates on a 7900HT ABI Prism Sequence Detection System (PE Applied Biosystems, Foster City, CA, USA) using SYBR Green PCR Master Mix (Applied Biosystems). All of the primers used for RT-PCR (IL-1 $\alpha$, IL-6, IL-10, TNF- $\alpha$, MUC2, TFF3, glyceraldehyde 3-phosphate dehydrogenase, B2M, ACTB, PPIA and YWHAZ) were designed using Primer Express $^{\mathrm{TM}}$ software (Applied Biosystems, Foster City, CA, USA) and were synthesised by MWG Biotech (Milton Keynes, UK). Primer sequence data are presented in Table 3. Amplification was carried out in a total volume of $20 \mu \mathrm{l}$ containing $10 \mu \mathrm{l} \mathrm{SYBR}$ PCR Mastermix, forward and reverse primer $(1 \mu \mathrm{l}), 8 \mu \mathrm{l}$ diethyl pyrocarbonate (DPEC)treated water and $1 \mu \mathrm{l}$ of template complementary DNA. All the samples were prepared in triplicate. The thermal cycling conditions involved an initial denaturation step at $95^{\circ} \mathrm{C}$ for $10 \mathrm{~min}$, forty cycles of $95^{\circ} \mathrm{C}$ for $15 \mathrm{~s}$ and $65^{\circ} \mathrm{C}$ for $1 \mathrm{~min}$. Dissociation analyses of the PCR product were performed to confirm the specificity of the resulting PCR products. The mean threshold cycle $\left(C_{t}\right)$ values of triplicates of each sample were used for calculations.

\section{Normalisation of data}

Normalisation of the $C_{\mathrm{t}}$ values obtained from real-time RT-PCR was performed by (i) transforming the raw $C_{\mathrm{t}}$ values to relative quantities using the formula, relative quantities $=(\operatorname{PCR} \text { efficiency })^{\Delta C_{\mathrm{t}}}$, where $\Delta C_{\mathrm{t}}$ is the change in the $C_{\mathrm{t}}$ values of the sample relative to the highest expression (minimum $C_{\mathrm{t}}$ value), (ii) using geNorm, a normalisation factor was obtained from the relative 
Table 3. Oligonucleotide sequence of forward and reverse primers used for RT-PCR*

\begin{tabular}{|c|c|c|}
\hline Gene name & $\begin{array}{l}\text { Forward primer }\left(5^{\prime}-3^{\prime}\right) \\
\text { Reverse primer }\left(5^{\prime}-3^{\prime}\right)\end{array}$ & $T_{\mathrm{m}}\left({ }^{\circ} \mathrm{C}\right)$ \\
\hline \multirow[t]{2}{*}{ IL-1 $1 \alpha$} & CAGCCAACGGGAAGATTCTG & $59 \cdot 4$ \\
\hline & AATGGCTTCCAGGTCGTCAT & 57.3 \\
\hline \multirow[t]{2}{*}{ IL-6 } & AGACAAAGCCACCACCCCTAA & $59 \cdot 8$ \\
\hline & CTCGTTCTGTGACTGCAGCAGCTTATC & 62.7 \\
\hline \multirow[t]{2}{*}{ IL-10 } & GCCTTCGGCCCAGTGAA & $57 \cdot 6$ \\
\hline & AGAGACCCGGTCAGCAACAA & 59.4 \\
\hline \multirow[t]{2}{*}{ TNF- $\alpha$} & TGGCCCCTTGAGCATCA & $55 \cdot 2$ \\
\hline & CGGGCTTATCTGAGGTTTGAGA & 60.3 \\
\hline \multirow[t]{2}{*}{ MUC2 } & CAACGGCCTCTCСTTCTCTGT & $63 \cdot 1$ \\
\hline & GCCACACTGGCCCTTTGT & 62.1 \\
\hline \multirow[t]{2}{*}{ TFF3 } & CTGCTTCGACTCCAGCATC & $58 \cdot 8$ \\
\hline & CAGAAGGTGCATTCTGTTTCC & 57.9 \\
\hline \multirow[t]{2}{*}{ GADPH } & CAGCAATGCCTCCTGTACCA & $62 \cdot 2$ \\
\hline & ACGATGCCGAAGTTGTCATG & 62.1 \\
\hline \multirow[t]{2}{*}{ B2M } & CGGAAAGCCAAATTACCTGAAC & $59 \cdot 0$ \\
\hline & TCTCCCCGTTTTTCAGCAAAT & 60.0 \\
\hline \multirow[t]{2}{*}{ ACTB } & CAAATGCTTCTAGGCGGACTGT & $59 \cdot 0$ \\
\hline & TCTCATTTTCTGCGCAAGTTAGG & 60.0 \\
\hline \multirow[t]{2}{*}{ PPIA } & CGGGTCCTGGCATCTTGT & 58.0 \\
\hline & TGGCAGTGCAAATGAAAAACTG & 56.5 \\
\hline \multirow[t]{2}{*}{ YWHAZ } & GGACATCGGATACCCAAGGA & $58 \cdot 0$ \\
\hline & AAGTTGGAAGGCCGGTTAATTT & 59.0 \\
\hline
\end{tabular}

quantities of four most stable housekeeping genes (GAPDH, B2M, ACTB and PPIA in both ileum and colon). Another housekeeping gene, YWHAZ, was found to be unstable (stability measure $M>1.5$ in both tissues) and therefore excluded for calculation of the normalisation factor and (iii) the normalised fold change or the relative abundance of each of the target genes was calculated by dividing its relative quantity by the normalisation factor.

\section{Statistical analysis}

The experimental data were analysed as a $2 \times 2$ factorial using the generalised linear model procedure of SAS ${ }^{(27)}$. The statistical model included the main effects of dietary SWE inclusion, FO inclusion and associated two-way interactions. The individual sow and the pen containing weaned pigs served as the experimental unit for all variables measured. The data were checked for normality using the Proc Univariate function of SAS. All the data presented in the tables are expressed as least square means with their standard errors. The probability value which denotes statistical significance is $P<0 \cdot 05$.

\section{Results}

\section{Growth performance}

The number of live born piglets, litter weight, average piglet birth weight and weaning weight were not influenced by sow dietary treatment (Table 4). The effect of maternal dietary supplementation on PW pig performance is presented in Table 5. Pigs weaned from SWEsupplemented sows had a higher average daily gain (ADG) between days 0 and $21(P=0.063)$ and higher average daily feed intake between days 7 and $14(P<0.05) \mathrm{PW}$ compared with non-SWE-supplemented sows. Pigs weaned from FO-supplemented sows had higher ADG $(P<0.05)$ and gain to feed ratio $(P<0.01)$ between days 7 and 14 PW compared with non- FO-supplemented sows. There was no significant interaction between maternal SWE and FO supplementation on PW pig performance.

Furthermore, dietary treatment of sows had no effect on performance of the killed pigs between days 0 and $9 \mathrm{PW}$. The ADG, average daily feed intake and gain to feed ratio were $0.195($ SD 0.030$) \mathrm{kg} / \mathrm{d}, 0.277$ (SD 0.120$) \mathrm{kg} / \mathrm{d}$ and 0.727 (SD 0.09$) \mathrm{kg} / \mathrm{kg}$, respectively, for the killed pigs.

\section{Selected microbial populations}

In the caecum, there was an interaction between maternal SWE and FO supplementation on $E$. coli populations (Table 6; $P<0.05)$ and Lactobacillus:E. coli ratio $(P<0.05)$ in pigs $9 \mathrm{~d} \mathrm{PW}$. Pigs weaned from SWE-supplemented sows had a reduced $E$. coli population and higher Lactobacillus:E. coli ratio in the caecum $(P<0.05)$ compared with pigs weaned from sows fed the basal diet; however, when the combination of SWE and FO was offered to sows, no effects were detected on $E$. coli numbers and Lactobacillus:E. coli ratio compared with FO-only diets. In the colon, pigs weaned from SWE-supplemented sows had lower Bifidobacterium populations (9.12 v. 8.32

Table 4. Effect of maternal dietary supplementation with seaweed extract (SWE) and fish oil (FO) from day 109 of gestation until weaning (day 26) on pre-weaning piglet performance $\dagger$

(Adjusted mean values with their pooled standard errors)

\begin{tabular}{|c|c|c|c|c|c|c|c|c|}
\hline \multirow[t]{2}{*}{ Treatment... } & \multicolumn{3}{|c|}{ SWE } & \multicolumn{3}{|c|}{$\mathrm{FO}$} & \multicolumn{2}{|c|}{$P^{*}$} \\
\hline & No & Yes & SEM & No & Yes & SEM & SWE & FO \\
\hline Litter size $(n)$ & 12.40 & 12.40 & 0.51 & $12 \cdot 40$ & $12 \cdot 35$ & 0.51 & 0.968 & 0.927 \\
\hline Litter weight (kg) & $15 \cdot 60$ & $15 \cdot 50$ & 0.61 & $15 \cdot 40$ & $15 \cdot 60$ & 0.61 & 0.937 & 0.820 \\
\hline Birth weight (kg) & $1 \cdot 26$ & 1.28 & 0.05 & 1.26 & $1 \cdot 27$ & 0.05 & 0.854 & 0.893 \\
\hline Weaning weight $(\mathrm{kg})$ & 8.29 & $7 \cdot 81$ & 0.26 & $8 \cdot 29$ & $7 \cdot 80$ & 0.26 & 0.127 & 0.134 \\
\hline ADG $(0-26 \mathrm{~d}, \mathrm{~kg} / \mathrm{d})$ & 0.263 & 0.255 & 0.008 & 0.266 & 0.251 & 0.008 & 0.501 & 0.235 \\
\hline
\end{tabular}

ADG, average daily gain.

* There was no significant interaction between maternal SWEXFO supplementation on pre-weaning piglet performance.

†Ten sows per treatment. 
Table 5. Effect of maternal dietary supplementation with seaweed extract (SWE) and fish oil (FO) from day 109 of gestation until weaning (day 26) on post-weaning pig performance

(Adjusted mean values with their pooled standard errors*)

\begin{tabular}{|c|c|c|c|c|c|c|c|c|}
\hline \multirow[t]{2}{*}{ Treatment... } & \multicolumn{3}{|c|}{ SWE } & \multicolumn{3}{|c|}{ FO } & \multicolumn{2}{|c|}{$P \dagger$} \\
\hline & No & Yes & SEM & No & Yes & SEM & SWE & FO \\
\hline \multicolumn{9}{|l|}{$A D G(\mathrm{~kg} / \mathrm{d})$} \\
\hline \multicolumn{9}{|l|}{ Days } \\
\hline $0-7$ & 0.091 & 0.104 & 0.018 & 0.089 & 0.106 & 0.018 & 0.634 & 0.518 \\
\hline $7-14$ & 0.282 & 0.335 & 0.017 & 0.278 & 0.340 & 0.017 & 0.042 & 0.016 \\
\hline $14-21$ & 0.450 & 0.476 & 0.019 & 0.485 & 0.441 & 0.017 & 0.351 & 0.115 \\
\hline $0-21$ & 0.275 & 0.308 & 0.012 & 0.284 & 0.299 & 0.012 & 0.063 & 0.403 \\
\hline \multicolumn{9}{|l|}{ ADFI $(\mathrm{kg} / \mathrm{d})$} \\
\hline \multicolumn{9}{|l|}{ Days } \\
\hline $0-7$ & 0.169 & 0.174 & 0.013 & $0 \cdot 167$ & 0.175 & 0.013 & 0.781 & 0.691 \\
\hline $7-14$ & 0.366 & 0.424 & 0.017 & 0.394 & 0.396 & 0.017 & 0.025 & 0.932 \\
\hline $14-21$ & 0.669 & 0.669 & 0.050 & 0.655 & 0.713 & 0.050 & 0.669 & 0.417 \\
\hline $0-21$ & 0.401 & 0.433 & 0.019 & 0.405 & 0.428 & 0.019 & 0.186 & 0.288 \\
\hline \multicolumn{9}{|l|}{ Gain:feed ratio } \\
\hline \multicolumn{9}{|l|}{ Days } \\
\hline $0-7$ & 0.444 & 0.532 & 0.080 & 0.456 & 0.519 & 0.080 & 0.439 & 0.583 \\
\hline $7-14$ & 0.764 & 0.779 & 0.030 & 0.699 & 0.844 & 0.030 & 0.719 & 0.002 \\
\hline $14-21$ & 0.692 & 0.741 & 0.032 & 0.755 & 0.678 & 0.032 & 0.289 & 0.107 \\
\hline $0-21$ & 0.634 & 0.692 & 0.030 & 0.639 & 0.686 & 0.030 & 0.258 & 0.407 \\
\hline
\end{tabular}

ADG, average daily gain; $A D F I$, average daily feed intake.

${ }^{*}$ For thirty pigs/treatment.

†There was no significant interaction between maternal SWEXFO supplementation on post-weaning pig performance.

colony-forming units/g digesta; SEM $0.195, P<0.01)$ and tended to have reduced $E$. coli $(5.34 v .4 .50$ colony-forming units $/ \mathrm{g}$ digesta; SEM 0.334, $P=0.093$ ) and Lactobacilli populations $(8.75 v .8 .17$ colony-forming units/g digesta; SEM $0.227, P=0.087)$ compared with pigs weaned from non-SWE-supplemented sows.

\section{Small-intestinal histology}

In the ileum and jejunum, there was a significant interaction between maternal SWE and FO supplementation on villous height $(P=0.055$ and $<0.05$, respectively) and the villous height to crypt depth ratio (Table 7; $P<0 \cdot 05$ ). Pigs weaned from SWE-supplemented sows had an increased villous height and villous height to crypt depth ratio in the ileum and jejunum $(P<0.05)$ at $9 \mathrm{~d}$ PW compared with pigs weaned from non-SWE-supplemented sows; however, when the combination of SWE and FO was offered, no further effect was observed on villous height and villous height to crypt depth ratio compared with FO diets.

In the duodenum, pigs weaned from FO-supplemented sows had a higher villous height to crypt depth ratio compared with non-FO-supplemented sows (1.29 v. 1.34; SEM 0.153, $P<0 \cdot 05)$.

Table 6. Effect of maternal dietary supplementation with seaweed extract (SWE) and fish oil (FO) from day 109 of gestation until weaning (day 26) on selected intestinal microflora of pigs $9 \mathrm{~d}$ after weaning

(Mean values with their pooled standard errors ${ }^{*}$ )

\begin{tabular}{|c|c|c|c|c|c|c|c|c|}
\hline \multirow{2}{*}{$\begin{array}{l}\text { FO supplementation }(\mathrm{g} / \mathrm{d}) \ldots \\
\text { SWE inclusion }(10.0 \mathrm{~g} / \mathrm{d})\end{array}$} & \multicolumn{2}{|c|}{0} & \multicolumn{3}{|c|}{100} & \multicolumn{3}{|c|}{$P$} \\
\hline & No & Yes & No & Yes & SEM & SWE & FO & SWEXFO \\
\hline$n$ & 10 & 10 & 10 & 10 & & & & \\
\hline \multicolumn{9}{|l|}{ Caecum ( $\log _{10} \mathrm{cfu} / \mathrm{g}$ digesta) } \\
\hline Bifidobacterium spp. & 8.52 & 8.57 & 8.54 & $8 \cdot 30$ & 0.211 & 0.652 & 0.563 & 0.506 \\
\hline Lactobacillus spp. & $8 \cdot 15$ & $8 \cdot 14$ & 8.41 & 7.93 & 0.328 & 0.466 & 0.926 & 0.486 \\
\hline Escherichia coli & 4.89 & 3.67 & 3.37 & $3 \cdot 78$ & 0.387 & 0.311 & 0.081 & 0.048 \\
\hline Ratio† & $1 \cdot 71$ & $2 \cdot 20$ & $2 \cdot 73$ & $2 \cdot 14$ & 0.213 & 0.804 & 0.034 & 0.019 \\
\hline \multicolumn{9}{|l|}{ Colon ( $\log _{10} \mathrm{cfu} / \mathrm{g}$ digesta) } \\
\hline Bifidobacterium spp. & 8.91 & 8.53 & $9 \cdot 32$ & $8 \cdot 11$ & 0.276 & 0.008 & 0.998 & 0.148 \\
\hline Lactobacillus spp. & $8 \cdot 50$ & 8.33 & 8.99 & 8.01 & 0.322 & 0.087 & 0.775 & 0.222 \\
\hline E. coli & 5.51 & 4.62 & $5 \cdot 16$ & 4.38 & 0.473 & 0.093 & 0.535 & 0.917 \\
\hline Ratiof & 1.53 & 1.91 & 1.80 & 2.09 & 0.206 & 0.115 & 0.285 & 0.809 \\
\hline
\end{tabular}

cfu, Colony forming units.

* For ten pigs/treatment.

† Lactobacillus: E. coli ratio. 
Table 7. Effect of maternal dietary supplementation with seaweed extract (SWE) and fish oil (FO) from day 109 of gestation until weaning (day 26) on villous height, crypt depth and villous height to crypt depth ratio in pigs $9 \mathrm{~d}$ after weaning

(Mean values with their pooled standard errors*)

\begin{tabular}{|c|c|c|c|c|c|c|c|c|}
\hline \multirow{2}{*}{$\begin{array}{l}\text { Fish oil }(\mathrm{g} / \mathrm{d}) \ldots \\
\text { SWE inclusion }(10.0 \mathrm{~g} / \mathrm{d})\end{array}$} & \multicolumn{2}{|c|}{0} & \multicolumn{3}{|c|}{100} & \multicolumn{3}{|c|}{$P$} \\
\hline & No & Yes & No & Yes & SEM & SWE & $\mathrm{FO}$ & SWEXFO \\
\hline$n$ & 10 & 10 & 10 & 10 & & & & \\
\hline \multicolumn{9}{|l|}{ Villous height $(\mu \mathrm{m})$} \\
\hline Duodenum & 419.4 & $415 \cdot 9$ & $430 \cdot 1$ & 421.5 & $5 \cdot 62$ & 0.291 & 0.183 & 0.645 \\
\hline Jejunum & 384.2 & $396 \cdot 2$ & 395.4 & $382 \cdot 8$ & 5.00 & 0.952 & 0.843 & 0.022 \\
\hline Ileum & $215 \cdot 0$ & 233.0 & 238.7 & $232 \cdot 6$ & 6.00 & 0.328 & 0.063 & 0.055 \\
\hline \multicolumn{9}{|l|}{ Crypt depth $(\mu \mathrm{m})$} \\
\hline Duodenum & 328.8 & 314.3 & $316 \cdot 0$ & $315 \cdot 4$ & 4.40 & 0.097 & 0.216 & 0.122 \\
\hline Jejunum & 288.6 & $280 \cdot 3$ & 291.7 & 288.1 & 6.87 & 0.392 & 0.458 & 0.731 \\
\hline Ileum & $178 \cdot 0$ & $172 \cdot 4$ & $167 \cdot 9$ & $171 \cdot 7$ & 4.75 & 0.853 & 0.270 & 0.333 \\
\hline \multicolumn{9}{|l|}{ Villous:crypt depth ratio } \\
\hline Duodenum & $1 \cdot 28$ & 1.31 & 1.36 & 1.32 & 0.02 & 0.788 & 0.049 & 0.164 \\
\hline Jejunum & 1.33 & 1.43 & 1.36 & 1.33 & 0.03 & 0.288 & 0.177 & 0.034 \\
\hline Ileum & 1.21 & 1.36 & 1.42 & 1.35 & 0.04 & 0.444 & 0.015 & 0.013 \\
\hline
\end{tabular}

${ }^{\star}$ For ten pigs/treatment.

\section{Volatile fatty acids}

Pigs weaned from FO-supplemented sows had lower molar proportion of butyric acid (0.068 v. 0.091; SEM $0.006, \quad P<0.01)$ in the caecum compared with nonFO-supplemented sows (Table 8).

In the colon, there was a significant interaction between maternal SWE and FO supplementation on the molar proportions of valeric acid $(P<0.05)$, isovaleric acid $(P<0.05)$, isobutyric acid $(P<0.05)$ and total branched-chain fatty acid $(P<0 \cdot 01)$. FO supplementation induced an increase in molar proportions of valeric acid, isovaleric acid, isobutyric acid and branched-chain fatty acids $(P<0.05)$ compared with the basal diet; however, there was no effect on molar proportions of valeric acid, isovaleric acid, isobutyric acid and branched-chain fatty acids with the combination treatment.

\section{Gene expression profiles}

Pigs weaned from SWE-supplemented sows had a higher ileal expression of TNF- $\alpha$ mRNA compared with

Table 8. Effect of maternal dietary treatment with seaweed extract (SWE) and fish oil (FO) from day 109 of gestation until weaning (day 26) on volatile fatty acid composition of intestinal contents of pigs $9 \mathrm{~d}$ after weaning (Mean values with their pooled standard errors*)

\begin{tabular}{|c|c|c|c|c|c|c|c|c|}
\hline \multirow{2}{*}{$\begin{array}{l}\text { Fish oil }(\mathrm{g} / \mathrm{d}) \ldots \\
\text { SWE inclusion }(10.0 \mathrm{~g} / \mathrm{d})\end{array}$} & \multicolumn{2}{|c|}{0} & \multicolumn{3}{|c|}{100} & \multicolumn{3}{|c|}{$P$} \\
\hline & No & Yes & No & Yes & SEM & SWE & FO & SWEXFO \\
\hline$n$ & 10 & 10 & 10 & 10 & & & & \\
\hline \multicolumn{9}{|l|}{ Caecum } \\
\hline Total VFA (mmol/g digesta) & $181 \cdot 7$ & $168 \cdot 0$ & $170 \cdot 4$ & $183 \cdot 2$ & $11 \cdot 20$ & 0.968 & 0.865 & 0.249 \\
\hline Acetic acid & 0.660 & 0.645 & 0.675 & 0.665 & 0.011 & 0.289 & $0 \cdot 124$ & 0.801 \\
\hline Propionic acid & 0.228 & 0.245 & 0.240 & 0.245 & 0.010 & 0.298 & 0.539 & 0.542 \\
\hline Butyric acid & 0.093 & 0.089 & 0.063 & 0.074 & 0.008 & 0.664 & 0.009 & 0.371 \\
\hline Isobutyric acid & 0.003 & 0.003 & 0.004 & 0.002 & 0.001 & 0.308 & 0.949 & 0.295 \\
\hline Valeric acid & 0.011 & 0.012 & 0.012 & 0.010 & 0.002 & 0.823 & 0.686 & 0.492 \\
\hline Isovaleric acid & 0.005 & 0.006 & 0.006 & 0.004 & 0.001 & 0.582 & 0.572 & 0.264 \\
\hline Acetic:propionic acid & 2.94 & $2 \cdot 68$ & $2 \cdot 84$ & $2 \cdot 75$ & 0.158 & 0.287 & 0.897 & 0.624 \\
\hline BCFA & 0.020 & 0.021 & 0.022 & 0.016 & 0.003 & 0.482 & 0.623 & 0.226 \\
\hline $\mathrm{pH}$ & $6 \cdot 17$ & $6 \cdot 27$ & 6.41 & 6.07 & 0.189 & 0.511 & 0.922 & 0.255 \\
\hline \multicolumn{9}{|l|}{ Colon } \\
\hline Total VFA (mmol/g digesta) & $151 \cdot 6$ & $146 \cdot 0$ & $128 \cdot 1$ & $168 \cdot 7$ & $12 \cdot 62$ & 0.177 & 0.974 & 0.080 \\
\hline Acetic acid & 0.658 & 0.631 & 0.672 & 0.663 & 0.014 & 0.209 & 0.113 & 0.521 \\
\hline Propionic acid & 0.216 & 0.229 & 0.281 & 0.232 & 0.356 & 0.617 & 0.344 & 0.386 \\
\hline Butyric acid & 0.087 & 0.010 & 0.087 & 0.077 & 0.012 & 0.799 & 0.268 & 0.269 \\
\hline Isobutyric acid & 0.007 & 0.008 & 0.012 & 0.006 & 0.002 & 0.080 & 0.317 & 0.043 \\
\hline Valeric acid & 0.011 & 0.016 & 0.019 & 0.012 & 0.002 & 0.705 & 0.471 & 0.038 \\
\hline Isovaleric acid & 0.012 & 0.013 & 0.021 & 0.010 & 0.002 & 0.053 & 0.222 & 0.028 \\
\hline Acetic:propionic acid & 3.07 & $2 \cdot 79$ & $3 \cdot 18$ & 2.95 & 0.184 & $0 \cdot 166$ & 0.462 & 0.883 \\
\hline BCFA & 0.030 & 0.036 & 0.052 & 0.028 & 0.005 & 0.127 & 0.195 & 0.009 \\
\hline $\mathrm{pH}$ & $6 \cdot 28$ & $6 \cdot 17$ & 6.48 & 6.44 & 0.119 & 0.554 & 0.063 & 0.783 \\
\hline
\end{tabular}

VFA, volatile fatty acid; BCFA, branched-chain fatty acids.

${ }^{*}$ For ten pigs/treatment. 
Table 9. Effect of maternal dietary supplementation with seaweed extract (SWE) and fish oil (FO) from day 109 of gestation until weaning (day 26) on selected gene expression (normalised relative abundance) in the ileum and colon of pigs $9 \mathrm{~d}$ after weaning (Adjusted mean values and pooled standard errors*)

\begin{tabular}{|c|c|c|c|c|c|c|c|c|}
\hline \multirow[t]{2}{*}{ Treatment... } & \multicolumn{3}{|c|}{ SWE } & \multicolumn{3}{|c|}{ FO } & \multicolumn{2}{|c|}{$P \dagger$} \\
\hline & No & Yes & SEM & No & Yes & SEM & SWE & FO \\
\hline \multicolumn{9}{|l|}{ Ileum } \\
\hline IL-1 $1 \alpha$ & 0.216 & 0.215 & 0.034 & 0.224 & 0.206 & 0.034 & 0.984 & 0.741 \\
\hline IL-6 & 0.212 & 0.166 & 0.032 & 0.197 & 0.181 & 0.032 & 0.325 & 0.747 \\
\hline TNF- $\alpha$ & 0.164 & 0.575 & 0.102 & 0.264 & 0.475 & 0.106 & 0.010 & 0.182 \\
\hline $\mathrm{IL}-10$ & 0.127 & 0.075 & 0.023 & 0.085 & 0.116 & 0.023 & 0.122 & 0.371 \\
\hline MUC2 & 0.518 & 0.724 & 0.132 & 0.635 & 0.608 & 0.132 & 0.281 & 0.859 \\
\hline TFF3 & 0.585 & 0.708 & 0.076 & 0.664 & 0.629 & 0.076 & 0.266 & 0.766 \\
\hline \multicolumn{9}{|l|}{ Colon } \\
\hline IL-1 $1 \alpha$ & 0.150 & 0.132 & 0.025 & 0.099 & 0.182 & 0.025 & 0.632 & 0.029 \\
\hline IL-6 & 0.170 & 0.124 & 0.026 & 0.102 & 0.193 & 0.026 & 0.236 & 0.024 \\
\hline TNF- $\alpha$ & 0.242 & 0.206 & 0.026 & 0.214 & 0.234 & 0.026 & 0.338 & 0.592 \\
\hline $\mathrm{IL}-10$ & 0.132 & 0.077 & 0.022 & 0.089 & 0.121 & 0.022 & 0.092 & 0.324 \\
\hline MUC2 & 0.490 & 0.508 & 0.095 & 0.616 & 0.381 & 0.095 & 0.733 & 0.182 \\
\hline TFF3 & 0.371 & 0.565 & 0.068 & 0.536 & 0.400 & 0.068 & 0.045 & 0.111 \\
\hline
\end{tabular}

* For ten pigs/treatment.

†There was a tendency for a SWEXFO interaction on ileal IL-10 mRNA expression $(P=0.086)$.

non-SWE-supplemented sows (Table 9; $P<0 \cdot 01$ ). In the colon, IL-1 $\alpha$ and IL-6 mRNA expression was higher in pigs weaned from FO-supplemented sows compared with non-FO-supplemented sows $(P>0.05)$. Furthermore, pigs weaned from SWE-supplemented sows had a higher mRNA abundance of TFF3 in the colon compared with non-SWE-supplemented sows $(P>0 \cdot 05)$.

\section{Discussion}

In the present investigation, pigs weaned from SWE (laminarin-fucoidan mix)-supplemented sows had an increased ADG during the starter period. Previous authors reported that dietary provision of a similar SWE during the PW period improved growth performance ${ }^{(13,14)}$. Furthermore, Dritz et al. $^{(28)}$ reported that dietary inclusion of yeastderived $\beta$-glucans increased growth performance of weanling pigs. To our knowledge, this is the first investigation examining the influence of maternal $\beta$-glucans and fucoidan supplementation on growth performance of weanling pigs. The present results further indicate that pigs weaned from FO-supplemented sows had a higher ADG and gain to feed ratio between days 7 and 14 PW. Numerous investigators have demonstrated that marine oil supplementation during lactation improved suckling piglet growth $^{(7,29)}$; however, literature pertaining to the beneficial effects on performance beyond the suckling period are inconsistent. Lauridsen \& Jensen ${ }^{(10)}$ observed that maternal FO supplementation favoured no improvement in piglet growth performance PW. In contrast, pigs weaned from sows offered dietary tuna oil during lactation were significantly heavier $7 \mathrm{~d}$ PW compared with those offered linseed oil $^{(9)}$. These results demonstrate that supplementing sows with SWE and FO from day 109 of gestation until weaning promoted growth performance of weaned pigs; however, the combination of SWE and FO failed to influence growth performance PW, indicating the absence of any synergistic effect of the combination treatment.

The present study demonstrates that pigs weaned from SWE- and FO-supplemented sows harboured a decreased caecal E. coli population 9d PW. This suggests an antimicrobial effect of maternal SWE and FO supplementation on neonatal bacterial colonisation whether mediated through alterations in sow faecal microflora composition or through nutritional influences via ingestion of colostrum and milk. Canibe \& Jensen ${ }^{(30)}$ proposed that maternal milk may contribute a profound influence on neonatal microbial colonisation, in addition to other external factors ${ }^{(31,32)}$. To our knowledge, no data are available in the literature on the effect of maternal SWE and FO supplementation on intestinal microbiota colonisation of piglets. However, Reilly et $a l{ }^{(12)}$ reported that dietary provision of a similar SWE to weanling pigs reduced enteric Lactobacilli and Enterobacteriaceae populations, suggesting a broad-spectrum antimicrobial property of laminarin and fucoidan. Unfortunately, selected microflora enumeration in sow faeces was not determined in the present study and thus may provide a possible avenue for future investigations.

Evidence in the literature suggests that dietary n-3 PUFA profoundly influences host immune responsiveness and resistance against numerous Gram-negative bacteria ${ }^{(33)}$. Pscheidl et al. ${ }^{(34)}$ reported that FO supplementation significantly reduced $E$. coli populations in the gastrointestinal tract of rats and concluded that the positive effect exerted by dietary $n-3$ PUFA was partially mediated through an enhancement of bacteria killing. Furthermore, the endogenous gastrointestinal microflora influences mucosal immunity by selectively eliminating presenting pathogens through a colonisation resistance-mediated pathway. In addition, fucoidans have been demonstrated to possess 
numerous biological functions, including antimicrobial properties $^{(35)}$.

The reduced caecal and colonic E. coli populations observed in the present study are an important observation with regard to pig health status, as various pathogenic strains of $E$. coli are widely recognised to constitute important roles in the pathogenesis and onset of PW diarrhoea $^{(36)}$. Melin et al. ${ }^{(37)}$ suggested that a reduced Enterobacteriaceae population may contribute toward alleviating the severity and incidence of PW diarrhoea. However, no clinical signs of PW diarrhoea were observed in the present experiment, as pigs were monitored on a daily basis. Nevertheless, the reduced E. coli numbers in pigs weaned from SWE-supplemented sows may relate to laminarin and/or fucoidan ingestion through the mammary milk; however, no attempt to measure mammary uptake of laminarin and/or fucoidan was performed in the present study.

Dietary SWE and FO supplementation to lactating sows exerted a positive influence on intestinal morphology in pigs 9d PW. An increase in villous height and villous height to crypt depth ratio in the jejunum and ileum mucosal surface was observed in pigs weaned from SWE- and FO-supplemented sows; however, no effect was observed with the combination treatment. The villous height to crypt depth ratio has previously been described as an important indicator of gut health ${ }^{(1)}$. The observed increase in villous height may attribute to a number of reasons. Firstly, numerous studies correlate alterations in gut morphology with a reduced feed intake immediately $\mathrm{PW}^{(38,39)}$. However, these results indicate no difference in the feed intake data of slaughtered pigs. Secondly, it is conceivable that improvements in gut morphology may partially relate to a reduced $E$. coli population, as was observed in the caecum and colon. However, E. coli enumeration was not performed in the ileum. Wang et al. ${ }^{(40)}$ suggested that improvements in gut morphology at the small-intestinal mucosal surface PW correlated with a suppressed pathogenic environment. Thirdly, Lopez-Pedrosa et $a l^{(41)}$ previously reported that piglet consumption of long-chain n-3 PUFA enhanced microvilli recovery from starvation-induced damage. Furthermore, it has previously been demonstrated that offering lactating sows a dietary source of $n-3$ PUFA enriched the plasma and adipose tissue $n-3$ PUFA content of suckled piglets at weaning, and the dietary impact on fatty acid composition persisted up to 3 weeks PW ${ }^{(10)}$. Furthermore, Morales-Lopez et al. ${ }^{(42)}$ reported that dietary provision of yeast-derived $\beta$-glucans to broilers improved the villous height of jejunal mucosa, although these authors observed no difference in growth performance. In relation to the present study, possible uptake of laminarin into mammary secretions and subsequent introduction to the neonatal gastrointestinal environment during suckling may have primed smallintestinal mucosal architectural structure; however, further studies are warranted to elucidate the exact mechanism responsible for observations on small-intestinal histology.

A transient gut inflammation has been reported in pigs a few days after weaning ${ }^{(3,43)}$. These results showed that maternal SWE and FO supplementation potentiated a tissue-specific inflammatory response in pigs 9d PW. An increase in TNF- $\alpha$ and TFF3 mRNA expression was observed in the ileum and colon, respectively, of pigs $9 \mathrm{~d}$ PW. Eicher et $a l .{ }^{(44)}$ reported that dietary provision of yeast-derived $\beta$-glucans to weanling pigs augmented intestinal mRNA expression of TNF- $\alpha$; however, literature examining the influence of maternal $\beta$-glucans supplementation on intestinal inflammatory cytokine expression in newly weaned pigs is limited. Furthermore, a non-medicated starter weanling diet was provided in the present study, suggesting a carryover effect from maternal dietary treatment that primed or sensitised intestinal immunity. This observation could be of particular importance because of the central role mediated by $\mathrm{TNF}-\alpha$ in cell-mediated immunity directed against intracellular pathogens ${ }^{(45)}$. Additionally, TNF- $\alpha$ regulates leucocyte recruitment through both up-regulation of adhesion molecules on vascular endothelial cells and induction of cytokine and chemokine synthesis $^{(46)}$. Therefore, these results suggest that maternal SWE supplementation enhances the immune status in newly weaned pigs.

In addition, the influence of maternal dietary treatment on MUC2 and TFF3 mRNA expression was investigated. The trefoil factor (TFF) comprises a family of peptides essential for epithelial restitution, thus maintaining mucosal integrity of the gastrointestinal tract ${ }^{(47)}$. The present results indicate that maternal SWE supplementation induced an increase in colonic TFF3 mRNA expression in pigs $9 \mathrm{~d}$ PW. Several biological effects mediated by TFF3 have been identified which include stimulation of epithelial cell migration and maintenance of intestinal mucosal barrier surface ${ }^{(48)}$. Therefore, up-regulation of TFF3 in the present study may benefit mucosal restoration by stimulating epithelial cell migration. The co-expression of TFF3 and MUC2 is recognised in epithelial cells ${ }^{(49)}$; however, an increase in MUC2 mRNA expression was not observed in ileum tissue. Furthermore, a previous study demonstrated that TFF3 protects intestinal epithelial cell insult from reactive oxygen species-induced damage normally experienced during inflammation ${ }^{(50)}$.

The mechanism responsible for the immunomodulating effect of maternal SWE supplementation could be mediated by mammary uptake of low-molecular-weight laminarin and its introduction to the suckling piglet gastrointestinal tract. Rice et al. ${ }^{(51)}$ demonstrated that laminarin delivered orally can be internalised by intestinal epithelial cells and gut-associated lymphoid tissue cells with eventual translocation into the systematic circulation. Therefore, it is conceivable that during the nursery period, piglets may have assimilated laminarin from mammary secretions and the observed immunomodulatory effects represent 
carryover effects from continuous stimulation of intestinal mucosa by laminarin.

In contrast, FO supplementation induced an increase in mRNA expression of the pro-inflammatory cytokines, IL-6 and IL- $1 \alpha$ in colonic tissue and tended to increase mRNA abundance of the anti-inflammatory IL-10 in ileal tissue. Lou et al. ${ }^{(52)}$ reported that dietary provision of FO during the PW phase induced an up-regulation of splenic IL-6 and IL-10 mRNA expression in pigs. Although IL-6 is generally considered a pro-inflammatory cytokine, IL-6 plays an important role in mediating B-cell activation and antibody production ${ }^{(53)}$. The present results indicate that FO provision during lactation tended to increase ileal IL-10 mRNA abundance. The anti-inflammatory cytokine IL-10 is widely recognised to inhibit pro-inflammatory cytokine synthesis $^{(54)}$ and direct immune polarisation toward antibody production ${ }^{(55)}$. Therefore, maternal FO supplementation regulated inflammatory cytokine expression in a tissue-specific manner in pigs $9 \mathrm{~d}$ PW with no detrimental effect observed on pig performance.

In conclusion, maternal SWE and FO supplementation from day 109 of gestation until weaning stimulates growth performance and starter feed intake in weaning pigs. Compared with data in the literature, the present study demonstrates the long-term impact, i.e. PW, of maternal dietary supplementation during lactation. Maternal dietary treatment improved small-intestinal morphology and reduced caecal E. coli populations in pigs 9d PW. Interestingly, maternal SWE and FO supplementation up-regulated intestinal pro-inflammatory cytokine expression; however, no deleterious effect was observed on performance. This suggests that localised modifications in intestinal inflammatory cytokine expression are not necessarily associated with systemic inflammation and growth depression. Collectively, these results suggest that supplementation of the late maternal diet with SWE and FO positively influenced gastrointestinal development in weanling pigs. However, further work is warranted to ascertain the relationship between acute intestinal inflammation and growth performance during the PW phase. In addition, further work will help decipher the exact mechanism by which maternal supplementation bestowed positive effects on intestinal architectural structure and selected microflora of the weaned pig.

\section{Acknowledgements}

Funding for this research was provided under the National Development Plan, through the Research Stimulus Fund, administered by the Department of Agriculture, Fisheries and Food. All the authors contributed to the writing of the manuscript and interpretation of the results, reviewing its content and all the authors approved the final version submitted for publication. J. V. O'. D. was the principal investigator responsible for the design of the experiment, supervision of data collection and statistical analysis.
T. S., S. G. L., B. P. L. and B. B. contributed toward data collection and laboratory collection. S. G. L. and B. B. contributed equally to laboratory work. None of the authors had a financial or personal conflict of interest in relation to the present study.

\section{References}

1. Pluske JR, Hampson DJ \& Williams IH (1997) Factors influencing the structure and function of the small intestine in the weaned pig: a review. Livest Prod Sci 51, 215-236.

2. McCracken BA, Spurlock ME, Roos MA, et al. (1999) Weaning anorexia may contribute to local inflammation in the piglet small intestine. $J$ Nutr 129, 613-619.

3. Pie S, Lalles JP, Blazy F, et al. (2004) Weaning is associated with an upregulation of expression of inflammatory cytokines in the intestine of piglets. J Nutr 134, 641-647.

4. Xu RJ, Wang F \& Zhang SH (2000) Postnatal adaptation of the gastrointestinal tract in neonatal pigs: a possible role of milk-borne growth factors. Livest Prod Sci 66, 95-107.

5. Calder PC (2002) Dietary modification of inflammation with lipids. Proc Nutr Soc 61, 345-358.

6. Rooke JA, Sinclair AG, Edwards SA, et al. (2001) The effect of feeding salmon oil to sows throughout pregnancy on preweaning mortality of piglets. Anim Sci 73, 489-500.

7. Mitre R, Etienne M, Martinais S, et al. (2005) Humoral defence improvement and haematopoiesis stimulation in sows and offspring by oral supply of shark-liver oil to mothers during gestation and lactation. Br J Nutr 94, $753-762$.

8. Rooke JA, Carranca C, Bland IM, et al. (2003) Relationships between passive absorption of immunoglobulin $G$ by the piglet and plasma concentrations of immunoglobulin $G$ at weaning. Livest Prod Sci 81, 223-234.

9. Rooke JA, Shanks M \& Edwards SA (2000) Effect of offering maize, linseed or tuna oils throughout pregnancy and lactation on sow and piglet tissue composition and piglet performance. Anim Sci 71, 289-299.

10. Lauridsen C \& Jensen SK (2007) Lipid composition of lactational diets influences the fatty acid profile of the progeny before and after suckling. Animal 1, 952-962.

11. Gardiner GE, Campbell AJ, O'Doherty JV, et al (2008) Effect of Ascophyllum nodosum extract on growth performance, digestibility, carcass characteristics and selected intestinal microflora populations of grower-finisher pigs. Anim Feed Sci Technol 141, 259-273.

12. Reilly P, O'Doherty JV, Pierce KM, et al (2008) The effects of seaweed extract inclusion on gut morphology, selected intestinal microbiota, nutrient digestibility, volatile fatty acid concentrations and the immune status of the weaned pig. Animal 2, 1465-1473.

13. Gahan DA, Lynch MB, Callan JJ, et al. (2009) Performance of weanling piglets offered low-, medium- or high-lactose diets supplemented with a seaweed extract from Laminariaspp. Animal 3, 24-31.

14. McDonnell P, Figat S \& O'Doherty JV (2010) The effect of dietary laminarin and fucoidan in the diet of the weanling piglet on performance, selected faecal microbial populations and volatile fatty acid concentrations. Animal 4, 579-585.

15. Ryan MT, Smith AG, O'Doherty JV, et al. (2010) Effects of nutrient supplementation with laminarin derived from Laminaria byperborea and Laminaria digitata on mucin gene expression in the porcine ileum. Livest Sci (Epublication ahead of print version 31 July 2010). 
16. Smith AG, Ryan MT, O'Doherty JV, et al. (2010) Effects of dietary supplementation with laminarin derived from Laminaria byperborea and Laminaria digitata on colonic mucin gene expression in pigs. Livest Sci (Epublication ahead of print version 13 July 2010).

17. Leonard SG, Sweeney T, Bahar B, et al. (2010) Effect of maternal fish oil and seaweed extract supplementation on colostum and milk composition, humoral immune response, and performance of suckled piglets. I Anim Sci $\mathbf{8 8}$, 2988-2997.

18. Read SM, Currie G \& Bacic A (1996) Analysis of the structural heterogeneity of laminarin by electrospray-ionisation-mass spectrometry. Carb Res 281, 187-201.

19. Brown GD \& Gordon $S$ (2005) Immune recognition of fungal $\beta$-glucans. Cell Microbiol 7, 471-479.

20. Yun CH, Estrada A, Van Kessel A, et al. (2003) $\beta$-Glucan, extracted from oat, enhances disease resistance against bacterial and parasitic infections. FEMS Immunol Med Microbiol 35, 67-75.

21. Berteau O \& Mulloy B (2003) Sulfated fucans, fresh perspectives: structures, functions, and biological properties of sulfated fucans and an overview of enzymes active toward this class of polysaccharide. Glycobiology 13, 29-40.

22. Lynch MB, Sweeney T, Callan JJ, et al. (2009) The effect of dietary Laminaria-derived laminarin and fucoidan on nutrient digestibility, nitrogen utilisation, intestinal microflora and volatile fatty acid concentration in pigs. J Sci Food Agric 90, 430-437.

23. Boudry G, Douard V, Mourot J, et al. (2009) Linseed oil in the maternal diet during gestation and lactation modifies fatty acid composition, mucosal architecture, and mast cell regulation of the ileal barrier in piglets. J Nutr 139, 1110-1117.

24. NRC (1998) Nutrient Requirements of Swine, 10th ed. Washington, DC: National Academic Press.

25. Pierce KM, Sweeney T, Brophy PO, et al. (2005) Dietary manipulation post weaning to improve piglet performance and gastro-intestinal health. Anim Sci 81, 347-356.

26. Pierce KM, Sweeney T, Brophy PO, et al. (2006) The effect of lactose and inulin on intestinal morphology, selected microbial populations and volatile fatty acid concentrations in the gastro-intestinal tract of the weanling pig. Anim Sci 82, 311-318.

27. Statistical Analysis Systems Institute (1985) Statistical Analysis Systems, 6.12 ed. Cary, NC: SAS Institute, Inc.

28. Dritz SS, Shi J, Kielian TL, et al. (1995) Influence of dietary beta-glucan on growth performance, nonspecific immunity, and resistance to Streptococcus suis infection in weanling pigs. J Anim Sci 73, 3341-3350.

29. Rooke JA, Sinclair AG \& Edwards SA (2001) Feeding tuna oil to the sow at different times during pregnancy has different effects on piglet long-chain polyunsaturated fatty acid composition at birth and subsequent growth. Br J Nutr 86, 21-30.

30. Canibe N \& Jensen B (2009) Influence of maternal faecal microflora on colonization of the newborn piglet. 11th International Symposium on Digestive Physiology of Pigs 2009 20-22 May 2009; Montbrio del Camp, Costa Daurada, Spain.

31. Perez P, Dore J, Leclerc M, et al. (2007) Bacterial imprinting of the neonatal immune system: lessons from maternal cells? Pediatrics 119, 724-732.

32. Martin R, Delgado S, Maldonado A, et al. (2009) Isolation of lactobacilli from sow milk and evaluation of their probiotic potential. J Dairy Res 76, 418-425.

33. Anderson M \& Fritsche KL (2002) (n-3) Fatty acids and infectious disease resistance. J Nutr 132, 3566-3576.
34. Pscheidl E, Schywalsky M, Tschaikowsky K, et al. (2000) Fish oil-supplemented parenteral diets normalize splanchnic blood flow and improve killing of translocated bacteria in a low-dose endotoxin rat model. Crit Care Med 28, 1489-1496.

35. Shibata H, Iimuro M, Uchiya N, et al. (2003) Preventive effects of cladosiphon fucoidan against Helicobacter pylori infection in Mongolian gerbils. Helicobacter 8, 59-65.

36. Melin L, Katouli M, Lindberg $\AA$, et al (2000) Weaning of piglets. Effects of an exposure to a pathogenic strain of Escherichia coli. J Vet Med B Infect Dis Vet Public Health 47, 663-675.

37. Melin L, Mattsson S, Katouli M, et al. (2004) Development of post-weaning diarrhoea in piglets. Relation to presence of Escherichia coli strains and rotavirus. J Vet Med B Infect Dis Vet Public Health 51, 12-22.

38. Kelly D, Smyth JA \& Mccracken KJ (1991) Digestive development of the early-weaned pig; effect of level of food intake on digestive enzyme activity during the immediate postweaning period. Br J Nutr 65, 181-188.

39. Pluske JR, Williams IH \& Aherne FX (1996) Villous height and crypt depth in piglets in response to increases in the intake of cow's milk after weaning. Anim Sci 62, 145-158.

40. Wang Y-Z, Shan T-Z, Xu Z-R, et al. (2007) Effects of the lactoferrin (LF) on the growth performance, intestinal microflora and morphology of weanling pigs. Anim Feed Sci Technol 135, 263-272.

41. Lopez-Pedrosa JM, Ramirez M, Torres MI, et al. (1999) Dietary phospholipids rich in long-chain polyunsaturated fatty acids improve the repair of small intestine in previously malnourished piglets. J Nutr 129, 1149-1155.

42. Morales-Lopez R, Auclair E, Garcia F, et al. (2009) Use of yeast cell walls; $\beta-1,3 / 1$, 6-glucans; and mannoproteins in broiler chicken diets. Poult Sci 88, 601-607.

43. McCracken BA, Gaskins HR, Ruwe-Kaiser PJ, et al. (1995) Diet-dependent and diet-independent metabolic responses underlie growth stasis of pigs at weaning. J Nutr 125, 2838-2845.

44. Eicher SD, McKee CA, Carroll JA, et al. (2006) Supplemental vitamin $\mathrm{C}$ and yeast cell wall $\beta$-glucan as growth enhancers in newborn pigs and as immunomodulators after an endotoxin challenge after weaning. J Anim Sci 84, 2352-2360.

45. Strangfeld A \& Listing J (2006) Bacterial and opportunistic infections during anti-TNF therapy. Best Pract Res Clin Rheumatol 20, 1181-1195.

46. Kips JC (2001) Cytokines in asthma. Eur Respiratory J 18, $24-33$.

47. Taupin D \& Podolsky DK (2003) Trefoil factors: initiators of mucosal healing. Nat Rev Mol Cell Biol 4, 721-732.

48. Dignass A, Lynch-Devaney K, Kindon H, et al. (1994) Trefoil peptides promote epithelial migration through a transforming growth factor beta-independant pathway. J Clin Invest 94, 376-383.

49. Sasaki M, Ikeda H, Ohira S, et al. (2004) Expression of trefoil factor family 1,2 , and 3 peptide is augmented in hepatolithiasis. Peptides 25, 763-770.

50. Tan X, Chen Y, Liu Q, et al. (2000) Prostanoids mediate the protective effect of trefoil factor 3 in oxidant-induced intestinal epithelial cell injury: role of cyclooxygenase-2. J Cell Sci 113, 2149-2155.

51. Rice PJ, Adams EL, Ozment-Skelton T, et al. (2005) Oral delivery and gastrointestinal absorption of soluble glucans stimulate increased resistance to infectious challenge. J Pharmacol Exp Ther 314, 1079-1086.

52. Luo J, Huang FR, Xiao CL, et al. (2009) Effect of dietary supplementation of fish oil for lactating sows and weaned piglets on piglet Th polarization. Livest Sci 126, 286-291. 
53. Rincon M, Anguita J, Nakamura T, et al. (1997) Interleukin (IL)-6 directs the differentiation of IL-4-producing $\mathrm{CD}^{+} \mathrm{T}$ cells. J Exp Med 185, 461-470.

54. de Waal Malefyt R, Abrams J, Bennett B, et al. (1991) Interleukin 10 (IL-10) inhibits cytokine synthesis by human monocytes: an autoregulatory role of IL-10 produced by monocytes. J Exp Med 174, 1209-1220.
55. Liblau RS, Singer SM \& McDevitt HO (1995) Th1 and Th2 $\mathrm{CD}_{4}^{+} \mathrm{T}$ cells in the pathogenesis of organ-specific autoimmune diseases. Immunol Today 16, 34-38.

56. Sauvant D, Perez JM \& Tran G (2004) Tables of Composition and Nutritional Value of Feed Materials. Pigs, Poultry, Cattle, Sheep, Goats, Rabbits, Horses, Fish. The Netherlands: Wageningen Academic Publishers. 